\title{
Para una sociología de los entornos y de las redes partidistas*
}

\author{
Frédéric Sawicki**
}

\begin{abstract}
Resumen
Este artículo constituye un alegato a favor del análisis societal de los partidos políticos estudiados en el marco de regímenes democráticos. Contrariamente a los trabajos que enfatizan la autonomización de los partidos políticos, se propone recurrir al estudio de las redes sociales para aprehender las fronteras difusas propias de los entornos partidistas. La objetivación de las redes no es una tarea fácil. Por tal razón, el artículo defiende la necesidad de desarrollar análisis localizados y comparativos de lo político, ilustrando esta propuesta a través del caso del Partido Socialista francés.
\end{abstract}

Palabras clave: Entorno partidista - redes sociales - análisis societal de los partidos políticos - análisis localizado de lo político - Partido Socialista francés.

\begin{abstract}
This paper advocates for a societal analysis of political parties studied in the context of democratic regimes. Instead of emphasizing the autonomization of political parties, it proposes to appeal to social networks analysis in order to capture the blurry frontiers that characterize the social milieu on which political parties rely on. The objectivation of networks is not an easy task. For this reason, the present work insists on the necessity of developing localized and comparative analysis of political parties, exemplifying this proposal with the case of the Frssqench Socialist Party.
\end{abstract}

Keywords: Partisan environment - social networks - societal analysis of political parties - localized analysis of politics - French Socialist Party.

* Traducido por Vladimir Sierpe y Camila Gutiérrez. Este trabajo se enmarca en el Proyecto de Investigación ECOS-CONICYT C05H01.

** Profesor de Ciencia Política de la Universidad París 1-Panthéon Sorbonne. Correo electrónico: frederic.sawicki@ univ-paris1.fr 
Esquematizando al extremo, se pueden clasificar los análisis sociológicos de los partidos políticos en dos grandes categorías, dependiendo si enfatizan su heteronimia o su autonomía respecto de las fuerzas sociales. Esta distinción encuentra, en parte, su origen científico en la oposición entre la tradición weberiana y la tradición marxista del análisis de lo político. Es sabido, en efecto, que para Max Weber (1922, 1971: 292) los partidos son principalmente agrupaciones que "tienen como objetivo procurar a sus jefes el poder", mientras que para los autores marxistas, conforme a la hipótesis de la determinación de la superestructura política por la infraestructura socioeconómica, la taxonomía de los partidos corresponde ante todo a aquélla de las clases o fracciones de clases sociales. Antonio Gramsci es, sin duda, el intelectual marxista que ha abordado la cuestión con mayor sistematicidad. Para él, no cabe duda que todo partido es "la expresión de un grupo social y de un solo grupo social". El que algunos partidos en competencia se presenten a sí mismos como los representantes de una misma clase social, u otros, en cambio, como la expresión de varias clases sociales, se explica, según Gramsci, por dos razones principales: por una parte, la existencia de intereses divergentes que fragmentan la clase dominante en igual número de fracciones (una idea ya presente en el 18 Brumario de Marx); por otra, la existencia de divergencias estratégicas en cuanto a los medios más aptos para favorecer los intereses de clase. Entre éstas, el principal desacuerdo se produce en torno a la pregunta sobre las alianzas con otros grupos sociales para conquistar o conservar el poder. Cabe sin embargo notar que, cuando está en juego la sobrevivencia del sistema de explotación económico (i.e. lo más fundamental), esas divergencias desaparecen y se reconstituye la unidad de los partidos de clase para formar un "bloque"1.

Por supuesto, esta manera de resumir las grandes corrientes de la sociología de los partidos políticos es a la vez demasiado reductora y ampliamente obsoleta. Por el lado de los análisis que Ilamaremos societales, las investigaciones inspiradas en el marxismo han sido mejoradas, incluso superadas: por una parte, gracias a trabajos que, apoyándose en la historia cultural y política comparada, han puesto en evidencia la diversidad y la complejidad tanto de los clivajes sociopolíticos de los diferentes Estados occidentales como de su expresión partidaria ${ }^{2}$. Por otra parte, innumerables estudios cuantitativos fundados en la recolección de cuestionarios aplicados a cuadros partidistas, militantes, adherentes o electores, han revelado su carácter socialmente heterogéneo así como la complejidad de las variables explicativas de la adhesión o identificación a un partido dado. Sin embargo, esas investigaciones no siempre lograron superar las aporías del marxismo aplicado al estudio de los partidos, o sea la reducción de éstos a "expresiones" de clivajes sociales. Tampoco lograron corregir

1 "La verdad teórica según la cual cada clase corresponde a un solo partido es demostrada, durante momentos decisivos, por el hecho de que las agrupaciones diversas que se presentan cada una como partido 'independiente' convergen finalmente en un bloque único. La multiplicidad que existía anteriormente tenía únicamente un carácter 'reformista', vale decir, que concernía solamente cuestiones parciales; en cierto sentido, se trataba de una distribución del trabajo político (útil, a pesar de sus límites); pero cada una de las partes presuponía a la otra, al punto de que en momentos decisivos, es decir precisamente cuando han entrado en juego asuntos fundamentales, se ha formado la unidad, ha emergido un solo bloque" (Gramsci, 1933: 28).

2 Véanse principalmente Lipset y Rokkan (1967: 1-64) y Seiler (1980). 
la poca atención prestada al trabajo práctico y simbólico efectuado dentro de los partidos, trabajo que termina alimentando, cuando no creando, dichos clivajes ${ }^{3}$. En algunos casos, los partidos contribuyen efectivamente no sólo a dar forma sino también a legitimar y a desplazar las líneas divisorias que atraviesan una sociedad determinada. A propósito del comunismo, el mismo S. Rokkan reconoció que el nuevo clivaje que instituyó era fruto de la revolución soviética así como del trabajo de difusión mundial -y con éxito variable- del modelo de partido bolchevique, de parte de la Internacional Comunista. Resumiendo, los análisis societales, si bien tienen el inmenso mérito de reencastrar los partidos políticos en la sociedad en la que despliegan sus actividades, han conducido frecuentemente a hacer de los partidos políticos cajas negras o inclusive entidades homogéneas en el tiempo y el espacio, en vez de empresas colectivas motivadas por intereses diversos, atravesadas por cambios incesantes, y susceptibles de usos muy diferenciados.

En la línea de la obra de Weber pero también de Ostrogorski (1903), Michels (1911) y luego Schumpeter (1942), las perspectivas organizacionales constituyen la segunda gran corriente de la sociología de los partidos. En su mayoría pasan por alto las características sociales de los miembros de los partidos y se focalizan en las luchas de poder que se desarrollan en su seno, es decir, esencialmente en los mecanismos de selección de dirigentes, en las luchas internas y en los recursos implementados para la conquista de posiciones de poder. Ampliamente dominante en ciencia política, conjuntamente con el análisis de sistemas de partidos, esta línea de investigación, simbolizada por el libro pionero de Maurice Duverger (1951), ha producido numerosos trabajos notables ${ }^{4}$. Según este planteamiento, los partidos ya no se asemejan a las cajas negras aludidas anteriormente, sino que son desmenuzados, y sobre todo clasificados en función de las formas de organización y de liderazgo que hacen su especificidad. En cuanto al "entorno" que determina sus estrategias, éste se encuentra en general reducido a variables políticas, principalmente al mismo sistema de partidos, al régimen político y al modo de escrutinio. Desde la famosa distinción construida por M. Duverger entre partidos de cuadros y partidos de masas, los investigadores en ciencia política se han esmerado en forjar nuevas categorías; las nociones de catch-all-party (Kirchheimer, 1966), stratarchic party (Eldersveld, 1964), electoral-professional party (Panebianco, 1982), y más recientemente de cartel-party (Katz y Mair, 1995)... han enriquecido progresivamente, y con diversa suerte, el léxico politológico, al ritmo de las mutaciones sociopolíticas.

\section{LA CONSTRUCCIÓN SOCIAL DE LAS ORGANIZACIONES POLÍTICAS}

Empero, desde la publicación del libro de Duverger, Georges Lavau, un politólogo francés, había vilipendiado "la explicación de los partidos por los partidos y por el régimen electoral", propuesta por Duverger, así como su decisión de considerar "'el' partido político como una 'comunidad con una estructura particular' caracterizada 'ante todo por su

\footnotetext{
3 Para una discusión crítica del enfoque sociocultural de los partidos políticos, véase Sartori (1990: 150-182).

4 Entre los textos teóricos más significativos se pueden citar: Eldersveld (1964); Kirchheimer (1966: 177-200); Schlesinger (1965: 764-801).
} 
autonomía'". G. Lavau (1953: 7) advertía así de forma anticipada sobre los límites de las tipologías exclusivamente organizacionales. "Un partido fascista puede perfectamente copiar su organización de la del Partido Comunista e insertarse en un mismo sistema partidario; el parecido sólo será morfológico, vale decir formal, y pasará por alto lo esencial, que sólo puede ser aprehendido mediante un análisis de la doctrina y de la composición social. En un grado menor, se podrían también observar diferencias fundamentales entre dos partidos comunistas, uno inserto en una sociedad de tipo agrícola y el otro en una sociedad de tipo industrial". Con lo que Lavau concluía: "Lo que falta a la obra de M. Duverger no es sólo el estudio de la doctrina y de la composición social de los partidos; más aún, es el estudio de los tipos de sociedad y de civilización en los que se desenvuelven los partidos, o de las condiciones económicas y circunstancias históricas en las cuales éstos evolucionan" (Lavau, 1983: 7, subrayado por el autor). Dicho de otra manera, "Ios partidos políticos no constituyen, en abstracto, comunidades definidas primero por su estructura: son ante todo grupos que provienen de una sociedad nacional determinada y, al interior de ésta, de grupos particulares formados en torno a intereses, afinidades o formas de sociabilidad más o menos diferenciados y caracterizados" (Lavau, 1953: 9).

La crítica de G. Lavau fue poco escuchada; luego cayó en el olvido, lo que se explica en parte por la débil cultura sociológica de numerosos especialistas en ciencia política de la época y se debe, por otra parte, a su carácter sin duda excesivo. De hecho, Lavau, al igual que Gramsci, minimiza en cierta medida los efectos de la profesionalización política, producto de la generalización del sufragio universal. La aparición de emprendedores especializados en la "pesca de votos" (representantes elegidos por votación popular a tiempo completo, permanentes de partidos, periodistas políticos...) ha conducido a estos últimos a desarrollar sus propias estrategias de preservación de sus posiciones. Estas estrategias pueden entrar en contradicción con los intereses de la clase social de la que provienen, incluso con los intereses de ciertos grupos que sin embargo pretenden representar, debido a la diversidad social de su electorado pero sobre todo a las estrategias de alianzas que se ven obligados a entablar para acceder o mantenerse en el poder ${ }^{5}$. Esta autonomización parcial del campo político justifica por ende plenamente el estudio, de manera autónoma, de la organización de los partidos y de las estrategias que nacen de su participación en el campo político, así como la elaboración de tipos ideales destinados a su comparación. Sin embargo, la tendencia a convertir la clasificación de partidos en la finalidad principal de la investigación y a ignorar las propiedades sociales de sus miembros ha conducido incontestablemente a simplificar el análisis. Cabe constatar, por ejemplo, que los estudios organizacionales no han sido muy capaces de explicar el surgimiento o la desaparición de ciertos partidos y, más generalmente, de dar cuenta de los cambios incesantes que atraviesan esas organizaciones ${ }^{6}$. La teoría del

5 La definición clásica del partido de LaPalombara y Weiner (1966) integra el éxito relativo de este proceso. Para aquellos autores, un partido es una organización duradera, nacionalmente estructurada y jerarquizada, cuyos dirigentes tienen como voluntad deliberada la conquista del poder mediante la adquisición de un apoyo popular, vía las elecciones o por cualquier otro medio. Acerca de la génesis de los partidos en las principales democracias occidentales, véase Pombeni (1985).

$6 \quad$ Esta crítica fue desarrollada por Lagroye (1989: 362-375). 
partido-cartel, particularmente en boga en Europa, a pesar de su carácter controvertido, ilustra a cabalidad la dificultad para pensar los partidos en articulación con su entorno social: defiende la hipótesis de que los partidos están cercenados de la sociedad y funcionan de manera aislada, sin explicar por qué la cartelización no logra alcanzar el mismo nivel de un país a otro, inclusive de un partido a otro $^{7}$.

Afortunadamente, algunos trabajos recientes han intentado superar la oposición intelectual relativamente esterilizante que se ha forjado progresivamente entre análisis societal y análisis organizacional, sentando las bases de una problemática en términos de construcción social de las organizaciones partidarias. La teoría propuesta por Michel Offerlé (1987) se revela desde este punto de vista particularmente interesante, al subrayar los impasses intelectuales a los que conduce la clasificación a secas de los partidos y su tratamiento como entidades reificadas. El análisis de M. Offerlé descansa principalmente en Weber (1922), Schumpeter (1942) y Pierre Bourdieu (1981, 1984). Retoma de los dos primeros los conceptos de "empresa", de "emprendedores políticos" y de "mercado", y de P. Bourdieu los de "campo" y de "disposiciones sociales". De esta forma, logra poner en relación los diferentes tipos de "empresas políticas" ${ }^{8}$ con las disposiciones y los recursos sociales de sus dirigentes, evitando por esa vía aprehender a los "emprendedores políticos" como simples estrategas débilmente determinados por sus disposiciones sociales. En este modelo, la forma tomada por la "relación partidista", abierta o cerrada, burocratizada o débilmente disciplinada, no aparece dada de una vez por todas: estrechamente dependiente de los recursos políticos y sociales de los dirigentes y de sus auxiliares, constituye también un eje central de los enfrentamientos entre los miembros del partido. Uno de los intereses principales de esta perspectiva reside, desde luego, en su voluntad de conciliar el estudio relacional de las disposiciones de los actores con el de sus estrategias o tomas de posición.

Esta pista fructífera ha sido explorada de forma ejemplar por Bernard Pudal (1988) en su análisis sobre la institucionalización del Partido Comunista Francés (PCF) durante los años treinta. En vez de imputar una fuerza intrínseca a la ideología comunista y al control por el Komintern, este politólogo pone en evidencia, recurriendo a la biografía individual y colectiva de cuadros partidistas, lo que predisponía socialmente a los primeros dirigentes comunistas a entregarse a la institución y a identificarse con ella, para luego convertir esta fidelidad en una norma absoluta de conducta militante. Deconstruyendo "al actor colectivo con el fin de reconstruir los procesos históricos y sociales mediante los cuales los actores individuales, en su diversidad, se agregan, se excluyen, se institucionalizan",

7 Compartimos aquí la crítica formulada por Ruud Koole (1996: 520): "Instead of using an evolutionary language, Katz and Mair could help us to understand their 'cartel party' better if they would concentrate on developing propositions about the forces that tend to produce parties of the alleged cartel type. Why do these parties develop in certain countries and not in others? Or: why can some parties be called cartel parties and others in the same country cannot be characterized as such?".

8 Para M. Offerlé un partido es una empresa política, vale decir, "un tipo particular de relación en la cual uno o más agentes invierten capitales con el fin de obtener ganancias políticas produciendo bienes políticos" (véase Offerlé, 1987: 22). 
B. Pudal (1988: 14) rompe con todo determinismo. Su enfoque comprensivo entrega además pautas de lectura particularmente pertinentes para entender la génesis del obrerismo del PCF (que encuentra una de sus expresiones en el culto a la personalidad de Thorez y de Stalin), el apego al marxismo-leninismo de sus elites dirigentes, el encuadramiento estricto por el partido de sus representantes elegidos por votación popular y más globalmente los fundamentos de sus conflictos internos.

Este trabajo conduce a flexibilizar el marco teórico definido por M. Offerlé. Aboga particularmente a favor de una perspectiva que reencastra el estudio de los partidos políticos en su contexto sociohistórico. La génesis del Partido Comunista en Francia aparece así inseparable de las transformaciones de la clase obrera francesa de posguerra ${ }^{9}$, de las trabas inherentes al sistema educativo que restringe la promoción escolar de los niños de las clases populares, o del desarrollo del pequeño y mediano sector público, del cual una fracción cada vez más importante integra el Partido Socialista y la CGT (Confederación General del Trabajo). Todos aquellos fenómenos generan "un conjunto heterogéneo de situaciones identitarias críticas de las que van a sacar provecho los partidarios de la adhesión a la Internacional Comunista" (Pudal, 1988: 35). En síntesis, aunque centrado en la organización, el estudio de B. Pudal demuestra que las acciones de los dirigentes comunistas y las creencias que los guían distan mucho de responder exclusivamente a finalidades estratégicas impuestas por las lógicas de competencia inherentes al partido y al sistema político. Se inscriben en una institución y en una sociedad determinada, que deben ser pensadas permanentemente en sus interdependencias ${ }^{10}$.

Prosiguiendo con el caso paradigmático del PCF, los estudios localizados que le fueron consagrados estos últimos años por cientistas políticos (Hastings, 1991), historiadores (Noiriel, 1984; Fourcaut, 1986) o sociólogos (Bonnet, 1972; Molinari, 1991; Retière, 1994) confirman la pertinencia de esta perspectiva y van aun más allá al mostrar que los dirigentes nacionales e internacionales están lejos de ser los únicos en participar en el trabajo de puesta en forma del partido como grupo y como representación. Intentando comprender los mecanismos mediante los cuales este partido ha logrado históricamente representar a diversos grupos sociales o corporaciones profesionales, esas investigaciones no sólo han puesto de relieve la diversidad de los usos de la organización y de la identidad comunistas, sino también la determinación del trabajo de movilización puesto en práctica en el partido mediante formas específicas de sociabilidad y de identidad local y/o sindical o profesional. Si bien, según Bernard Pudal, el centralismo democrático y el obrerismo se explican por la relación peculiar que los cuadros dirigentes mantienen con la identidad obrera, esas monografías establecen que el "comunismo popular"11, en su diversidad, lleva la impronta de los grupos sociales que lo han conformado a nivel local. El "centralismo democrático" y la ideología marxista-

9 Respecto a las transformaciones, la mejor síntesis sigue siendo la de G. Noiriel (1986).

10 Desde este punto de vista, el enfoque de B. Pudal resulta más satisfactorio que el de A. Panebianco (1982), que tiende a considerar la dependencia institucional de manera fija y determinista, al punto de hablar de un modelo genético.

11 Retomando la expresión de Bonnet (1972). 
leninista aparecen así interpretados de manera a veces muy alejada de la idea común que uno tiene de ellos y de la que intentan imponer sus dirigentes. La utopía comunista es objeto de apropiaciones múltiples ${ }^{12}$. Se puede incluso decir que el comunismo sólo ha logrado triunfar en donde ha podido encontrar formas de utopía popular preconstituidas, compatibles con su gramática simbólica. No logró conquistar el cuasi monopolio de la representación obrera en Francia entre fines de los años treinta y fines de los años setenta imponiendo su ideología desde fuera. Lo hizo más bien cristalizando aspiraciones utópicas anteriores, las cuales fueron acarreadas en particular por el sindicalismo y las asociaciones obreras y campesinas. Por consiguiente, los éxitos de la empresa de movilización comunista ${ }^{13}$ deben ser aprehendidos de igual forma como el producto del trabajo de sus dirigentes internacionales y nacionales y como el resultado de múltiples entregas identitarias de grupos con expectativas extremadamente diversificadas. Tanto el discurso como la práctica comunistas lograron reunirlas simbólicamente.

\section{APREHENDER LA IMPLANTACIÓN SOCIAL Y LA ACTIVIDAD DE LOS PARTIDOS POLÍTICOS MEDIANTE EL ANÁLISIS DE REDES}

Las investigaciones recientes llevadas a cabo en sociología de los partidos políticos en Francia, pero también, por ejemplo, en Gran Bretaña ${ }^{14}$, han abierto oportunamente nuevas pistas de investigación que apuntan a no separar el análisis de las formas organizacionales, prácticas militantes o estrategias políticas del análisis de las propiedades sociales de dirigentes y miembros abordadas de manera relacional y comprensiva.

Dichas investigaciones muestran que no se pueden disociar las organizaciones partidistas de su entorno, si se busca comprender cómo determinado partido logra implantarse en una sociedad dada. Aproximándose lo más posible al terreno, vale decir a nivel local, se constata fácilmente la porosidad de las fronteras entre los partidos políticos y su entorno social. Existe así un continuo de relaciones entre dirigentes, militantes, adherentes, simpatizantes y electores. En este sentido, el partido descansa en redes relacionales que se entrecruzan, que son basadas en valores o intereses compartidos, y alimentadas mediante interacciones en diversos lugares de sociabilidad más o menos formales: asociaciones, sindicatos, cooperativas, mutuales, cafés... Propuse llamar entorno partidista al conjunto de esas relaciones sociales y recurrir al análisis de redes para objetivar los contornos del entorno partidista (Sawicki, 1997).

Insistir en la importancia de las redes apunta a realizar observaciones más finas acerca de las trayectorias militantes y dirigenciales de los partidos, abarcando en particular la diversidad de su reclutamiento en un mismo partido político, según los lugares y las épocas. Permite delimitar mejor las fronteras del entorno partidista, concebido como el conjunto

12 Este punto aparece también cuando se comparan a escala nacional los diferentes partidos comunistas, tal como hace Marc Lazar (1992) con Francia e Italia.

13 Respecto de esta noción y de su aplicación en ciencia política, véase Lacroix (1985: 469-565).

14 Véase el número 81 (2008) de la revista Politix. Sciences Sociales du Politique, dedicado a "La fabrique des partis en Grande-Bretagne", editado por F. Sawicki y Ph. Vervaeke. 
de relaciones consolidadas entre grupos cuyos miembros no tienen necesariamente como finalidad principal participar en la construcción del partido político, aunque contribuyan a aquello mediante sus actividades. La puesta en evidencia de las redes no constituye un fin en sí mismo. Sirve para develar, tal como escribe el antropólogo John A. Barnes (1969: 74), "entre otras cosas, las fronteras y la estructura interna de los grupos", en nuestro caso la estructura de relaciones estables e históricamente constituidas entre sectores sociales formalmente separados (político, sindical, económico, familiar, religioso...). De hecho, la mayoría de los partidos políticos no son burocracias. Si bien son gobernados en la cúpula por dirigentes profesionalizados, quienes se reúnen regularmente a nivel local aparecen como organizaciones ágiles e informales o incluso como nebulosas, como mostró por ejemplo Mildred Schwartz (1990) a propósito del Partido Republicano en Illinois ${ }^{15}$. Ese lado informal no constituye en absoluto una debilidad. Manifiesta, al contrario, la inscripción del vínculo partidista en el entramado de las relaciones cotidianas.

En ciencias sociales, el término "red" es utilizado para calificar una gran diversidad de cadenas de relaciones sociales no sólo entre individuos. En el campo de la sociología de las ciencias y de las técnicas así como de las ciencias de la comunicación, sirve en particular para analizar las relaciones entre individuos, grupos, organizaciones y "objetos"16: se habla entonces de "redes socio-técnicas". Asimismo, el análisis organizacional se interesa cada vez más por las redes entre organizaciones, por ejemplo, en el ámbito de las empresas por las relaciones entre abastecedores, subcontratistas y clientes considerados como "bloques". Estos diferentes usos de la noción de red y los riesgos de confusión que esto conlleva obligan a definir previamente el término. En lo que a mí respecta, me limitaré a las redes interindividuales. Sin embargo, resulta importante, si se quiere hacer del análisis de redes una herramienta empírica rigurosa, distinguir los diferentes tipos de redes interindividuales que pueden ser encontrados al estudiar un partido político. Distinguiré, por mi parte, por lo menos cinco:

1. La red como conjunto de relaciones personales (poco importa sobre qué son fundadas aquellas relaciones: la amistad, la familia, la vecindad, la religión, la profesión, el clientelismo...) formales o informales de un individuo dado (ego). Aquí, se trata de alguna manera de medir el capital social de un individuo singular, su densidad, su intensidad y su extensión en el espacio social. En ciencia política, esta acepción, como lo ha notado David Knoke (1990), puede ser particularmente útil para analizar la influencia política de "notables" o de bosses de grandes ciudades estadounidenses. La característica de la red personal del notable o del boss consiste precisamente en

15 M. Schwartz tiene sin embargo una concepción menos amplia del entorno partidista. Considera al partido como "una red de actores individuales y colectivos cuyas actividades separadas y cuyos compromisos tienen un objetivo partidista" (véase Schwartz, 1990: 257). Un representante electo por votación popular, miembro de un partido político que brinda un servicio personal a un elector, no lo hace obligatoriamente con el objetivo de reforzar la dominación de su partido. Sin embargo, su comportamiento tiene muchas probabilidades de producir ese efecto.

16 Véase por ejemplo la teoría del “actor-red” propuesta por Latour (2005). 
tener relaciones en entornos sociales muy diferentes, pero también en la administración y en los círculos de poder extralocales. De esta forma, se logra ocupar una posición nodal, vale decir, de intermediario (broker) o de filtro (gate-keeper) para acceder a numerosos recursos.

2. Pero la red puede remitir a una realidad controlada en mayor medida por los actores, es decir, a un sistema de afinidades duraderas fundado en intereses comunes, en lazos de dependencia o de obligaciones, entre individuos que deciden aliarse dentro de una organización o de un sector dado de la sociedad. En los partidos políticos, ese tipo de "alianza" caracteriza los cliques ${ }^{17}$, grupos primarios poco institucionalizados en oposición a las facciones estatutarias o manifiestas. Estos cliques pueden descansar sólo en intereses coyunturales, pero pueden igualmente tener un carácter más duradero y reunir agentes provenientes de una misma región, de una misma generación o profesión.

3. La red puede también designar al sistema de relaciones estabilizadas entre individuos quienes ocupan posiciones, homólogas o no, en sectores de actividad distintos, pero que están obligados a cooperar. El politólogo francés Michel Dobry (1986) Ilama a este tipo de red, "red de consolidación", en el sentido en que vuelve posibles las "transacciones colusivas" entre sectores sociales separados. Este concepto se aplica bien, según él, al funcionamiento del Estado central, por ejemplo a las relaciones entre poder político y sector militar. También se podría aplicar a las relaciones entre quienes ocupan cargos de elección popular y representantes del Estado. Los sociólogos de las empresas se han interesado en particular en este tipo de red, que remite a las relaciones regulares establecidas entre actores pertenecientes a diferentes organizaciones que no se encuentran reguladas por una autoridad legítima o por una relación mercantil (la compra de prestaciones, por ejemplo) ${ }^{18}$.

4. El concepto de red, en una acepción cercana a la anterior, puede también remitir a un sistema estabilizado (hasta institucionalizado) de interdependencia entre organizaciones que intervienen en diferentes sectores, pero cuyos actores son multiposicionados ${ }^{19} \mathrm{O}$ cuyos miembros comparten las mismas creencias o ideales. A mi juicio, los lazos entre dirigentes y militantes de partidos y activistas de grupos de interés atañen típicamente a esta categoría. Las relaciones regulares entre los actores de estos diferentes mundos son constitutivas de redes, las cuales no están ligadas a personas, pero se inscriben a menudo en el largo plazo. La mayoría de las veces estas redes no están formalizadas ni contractualizadas, a diferencia de lo que sucede en el ámbito económico.

17 N.d.T.: El término clique ha sido conservado en el léxico del análisis de redes en castellano. Un clique es un subconjunto de miembros unidos por obligaciones recíprocas.

18 Aunque puedan fundarse en intercambios informales pero regulares de informaciones, estas redes son a menudo consolidadas mediante contratos (joint ventures, alianzas estratégicas, consorcios de investigación, acuerdos de outsourcing) y existen entonces en cierto modo fuera de los individuos. Véase Podolny y Page (1998: 57-76).

19 La multiposicionalidad hace referencia a los individuos que intervienen en diferentes campos sociales y poseen por este hecho recursos adicionales que pueden importar, bajo ciertas condiciones, de un campo hacia otro. Sobre esta noción, véase Boltanski (1973: 3-26). 
5. Conviene agregar a estos cuatro tipos un quinto que engloba al conjunto de relaciones interpersonales entre los responsables de los diferentes componentes de una organización dada. La consignación rigurosa del conjunto de esas relaciones sólo puede realizarse en el marco de entidades restringidas (una pequeña empresa ${ }^{20}$, una asociación por ejemplo). No obstante, nada impide inferir, a partir de la mayor o menor frecuencia de las relaciones entre algunos actores de una misma organización de mayor tamaño, los mecanismos de coordinación informal que permiten gobernar una organización. Mildred Schwartz (1990), por ejemplo, estudió las relaciones entre los diferentes componentes del Partido Republicano en Illinois, en particular entre las distintas instituciones públicas controladas por sus miembros ${ }^{21}$. El énfasis en esta concepción de la red aparece especialmente apropiado cuando se trata de estudiar las relaciones entre los diversos lugares de poder que componen un partido político: grupo parlamentario o grupos políticos de colectividades locales, círculos presidencial o ministerial, dirección nacional o local del partido...

Cualquiera sea el tipo de red considerado, ninguno se reduce a relaciones interpersonales sin lazos con las posiciones y los roles sociales ocupados por los actores. Se tiende a oponer sistemáticamente las relaciones formales, es decir, fundadas en relaciones codificadas y a menudo jerarquizadas, con las relaciones informales; en otras palabras, se tiende a oponer la organización a la red. En la realidad, los actores tejen relaciones informales en el marco de sus actividades dentro de las organizaciones, pertenezcan a la misma organización o a organizaciones diferentes ${ }^{22}$. Las posiciones y los roles que los individuos ocupan en el mundo social les abren la posibilidad de insertarse en redes existentes y de modificar así eventualmente la forma adoptada por aquéllas. No existe entonces por un lado el mundo de la acción organizada y por otro el mundo de las redes. Se trata de dos facetas de la misma realidad social: por una parte, los roles y las posiciones ligados a determinados recursos y coacciones; por otra, los usos que los actores hacen de éstos. En palabras del antropólogo social sueco Ulf Hannerz: "La noción de red es muy útil en cuanto uno se interesa en los individuos y en el uso que éstos hacen de sus roles (en plural) más que en roles y en la manera en que invisten a individuos; en prácticas que juegan con límites institucionales o los atraviesan, más que en prácticas que los confirman" (1983: 223).

El secretario de una sección de un partido político, en la medida en que le interesa cumplir a cabalidad con su rol y consolidar su posición, debe tejer relaciones con las personas claves en su territorio para favorecer el dinamismo del partido (líderes asociativos, representantes elegidos por votación popular, funcionarios, periodistas, líderes de opinión...);

20 Remitimos, por ejemplo, al trabajo del sociólogo Emmanuel Lazega (2001) sobre los bufetes de abogados. El análisis de red global que éste propone es según él particularmente adaptado al estudio de las organizaciones colegiadas, es decir, débilmente burocratizadas y jerarquizadas.

21 Mildred Schwartz recalca a propósito del Partido Republicano que "el partido está organizado jerárquicamente, pero no en términos de relaciones de dominación, sino como un agregado de sectores interdependientes" (véase Schwartz, 1990: 267).

22 Al contrario, muchas asociaciones u organizaciones en el ámbito de la acción colectiva descansan en redes informales de sociabilidad. 
puede apoyarse en un capital social acumulado previamente a la posición que ocupa (un secretario de sección, ex sindicalista y un alto funcionario territorial no cuentan de partida con los mismos recursos), pero sucede a menudo que es esta posición de partida la que lo incita y predispone a tejer esos lazos. Estos últimos son la mayoría de las veces informales -excepto en los partidos que tienen lazos orgánicos con tal o cual sindicato, asociación o mutual-, pero sólo cobran sentido en función de la forma de estructuración de un partido en un territorio dado. El responsable de un partido cercano a círculos religiosos debe mantener relaciones con los miembros de las autoridades religiosas y los activistas de las asociaciones caritativas o de carácter social; al actuar así, contribuye a perpetuar un "sistema de acción" en el sentido de Michel Crozier y Ehrard Friedberg (1977) o una configuración según la expresión de Norbert Elias (1970), lo que Ilamo por mi parte "entorno partidista".

El análisis en términos de redes es efectivamente estructural y no individualista: en este sentido, no debe dar la impresión de que los actores son capaces de tejer relaciones de manera estratégica o instrumental. Aplicado a los partidos, tiene el mérito de permitir enfocar las actividades y las formas de organización partidistas como productos particulares de relaciones concretas entre individuos y grupos, que actúan simultáneamente en espacios sociales diferenciados. Este tipo de análisis conduce a percatarse de que las "estrategias" de los actores resultan tanto de sus posiciones en el entorno partidista y de los intereses o recursos ligados a éstas, como de los cálculos indisociables del marco de competencia interna propia de la organización partidista. Asimismo, el enfoque de redes ofrece una herramienta para dar cuenta de las homologías existentes entre el funcionamiento del partido o de algunas de sus tendencias y aquel propio de otras organizaciones (sindicatos, asociaciones...). Permite no perder de vista el hecho de que la competencia política (en torno a los puestos de poder) se juega también en toda una gama de organizaciones que van desde los sindicatos a ciertas asociaciones pasando por las empresas públicas o las administraciones. Más fundamentalmente, el concepto de red invita a explorar los mecanismos que explican que los profesionales de la política no actúan únicamente por cuenta propia, a riesgo de perder los recursos que les significa el conjunto de redes en las cuales están inmersos.

Los políticos, al igual que otros actores sociales, y al revés del modelo del rational choice, no sólo son homo œconomicus; jamás actúan por cuenta propia en virtud de un cálculo egoísta dictado por la sola racionalidad de la organización o del mercado, pues, como señala Jeremy Boissevain (1974: 6), "el individuo es dependiente de los demás, le resulta imposible realizar su interés personal sin tomar en consideración los intereses de los demás y sin poder demostrar que su acción les va a ser provechosa o por lo menos no les va a perjudicar". Llamar la atención sobre las redes que encierran a los actores políticos equivale entonces a incorporar al análisis su multiposicionalidad así como la pluralidad de los modos de relaciones y de las formas de intereses que se derivan de éstas. En la práctica, las relaciones de amistad o de fidelidad no son menos importantes para comprender las interacciones políticas que la dimensión conflictiva y competitiva. Dichas relaciones pueden fundarse en múltiples intercambios de servicios o en recuerdos compartidos ligados a la participación en luchas comunes. A ellas se superponen a menudo las relaciones de parentesco, producto de la estrechez de las redes militantes. 


\section{LA OBJETIVACIÓN DE LAS REDES PARTIDISTAS: EL EJEMPLO DEL PARTIDO SOCIALISTA FRANCÉS}

Sin embargo, la objetivación de las redes no es una tarea fácil. Resulta relativamente fácil cuando uno se interesa en un solo individuo del que se esfuerza por consignar el conjunto de relaciones sociales o en un pequeño grupo del que se procura censar el conjunto de interacciones entre sus miembros. En cambio, se torna muy difícil cuando uno está confrontado con organizaciones amplias y ramificadas como son los partidos políticos. Si bien este obstáculo ligado al tamaño impide una contabilización rigurosa, no es dirimente. Para identificar las redes en las cuales descansa el Partido Socialista (PS) francés, he combinado por mi parte dos enfoques: un análisis del partido en algunos sitios locales escogidos sobre la base de ciertas características típicas (influencia más o menos importante del partido, antigüedad variable de su implantación, diversidad de las características socioeconómicas y culturales de los territorios...) y un estudio fino de la trayectoria social y "militante" de cuadros partidistas, representantes elegidos por votación popular y militantes, a partir de cuestionarios y de entrevistas biográficas en profundidad ${ }^{23}$. Escoger un terreno geográficamente circunscrito permite a la vez prestar atención a las particularidades locales y aprehender mejor la densidad de ciertas redes sociopolíticas. Llevar a cabo una encuesta intensiva sobre los cuadros partidistas, los representantes elegidos por votación popular y los militantes, aprehendidos en su contexto cotidiano de acción, permite por su parte poner en evidencia las conexiones existentes entre el partido y ciertas organizaciones sindicales, patronales o religiosas, pero también ciertas familias o barrios. La encuesta de terreno ofrece la posibilidad de comprender mejor la naturaleza y frecuencia de estas relaciones, al permitir recolectar informaciones acerca de las políticas locales o de las tomas de posición del partido a favor de uno u otro de aquellos grupos. Obviamente, la atención puesta en las relaciones clientelares forma parte integrante del análisis: el examen de quien saca provecho en prioridad de la distribución de bienes políticos personalizados es a menudo uno de los elementos más reveladores de las connivencias entre el partido y tal o cual grupo social24.

Comparando la sociología de los principales dirigentes y representantes elegidos por votación popular de tres federaciones del PS francés en los años ochenta, logré poner en evidencia la existencia de proximidades muy diferentes según los territorios con diversos círculos y organizaciones. La imagen que se desprende de aquello es por cierto y ante todo la de un partido menos homogéneo de lo que se cree. En el departamento de Pas-de-Calais, región marcada por la industria y la explotación carbonífera, el PS ha conservado un fuerte anclaje en el mundo obrero gracias a los lazos con activistas asociativos y sindicales, y

23 Resumo aquí brevemente el método y los principales resultados de mi estudio sobre el PS en los departamentos de Pas-de-Calais (región industrial del norte de Francia), Ille-et-Vilaine (región dominada por el sector terciario público de Bretaña) y Var (región a la vez vitícola y turística del sur de Francia a orillas del Mediterráneo). Véase Sawicki (1997).

24 Cesare Mattina puso así en evidencia los lazos privilegiados entre el PS en Marsella y ciertas minorías étnicas o regionales (corsos, armenios esencialmente). Véase Mattina (2004, 2007). 
la presencia muy fuerte de representantes elegidos por votación popular. Éstos, aunque profesionales docentes en su mayoría, son en general de origen popular, con un $90 \%$ nativos del territorio. El anclaje del partido se explica también por el mantenimiento de un dispositivo importante de sociabilidad (fiestas, organización de rifas...) y de ayuda mutua. La legitimidad del PS pasa por un discurso de reivindicación territorial muy marcado que exige reparaciones por los daños causados por el fin de la explotación carbonífera. En Ille-et-Vilaine, así como en Bretaña, el PS se desarrolló a principios de los años setenta apoyándose en militantes originarios de sindicatos y asociaciones católicas, pero también en militantes provenientes de ámbitos anticlericales orientados hacia la defensa de la escuela pública en una región muy católica. El injerto prendió con dificultad, al punto que este clivaje seguía estructurando al partido a principios de los años noventa. Pero los militantes de origen cristiano importaron hacia el partido un espíritu tolerante y pragmático que terminó imponiéndose, contribuyendo a convertir al PS en heredero de la democracia cristiana. Por último en el Var, tercer terreno estudiado, este viejo departamento republicano y de izquierda de la Costa Azul se inclinó a finales de los años setenta hacia la derecha debido a la urbanización masiva que conoció el departamento a raíz del auge turístico y del aflujo importante de jubilados acomodados que escogieron la zona para su retiro. Esencialmente implantado en el ámbito rural y en las ciudades pequeñas, el PS no estuvo en condiciones de desarrollar sus redes en los nuevos centros urbanos. Fundada en lazos interpersonales basados a menudo en el clientelismo y en la familia, la dominación del PS ha sido progresivamente corroída a medida en que éste iba perdiendo los recursos públicos que controló durante mucho tiempo (los municipios pero sobre todo el "Consejo General", instancia de gobierno departamental, particularmente importante para las comunas rurales que no disponen de suficientes recursos para asumir solas sus gastos).

Aunque compartamos la inmensa mayoría de los supuestos paradigmáticos del structural analysis, tal como se ha desarrollado en los Estados Unidos desde hace una veintena de años (Wellmann y Berkowitz, 1988), nuestro enfoque descansa más bien en un método más inductivo y más cercano al que utilizaron los antropólogos sociales ingleses. Estos fueron los primeros importadores hacia las ciencias sociales ${ }^{25}$ del concepto de "interaccionismo estructural" que resume adecuadamente los supuestos de este enfoque analítico. El uso más flexible del concepto de red permite incorporar mejor la historia y el cambio social, algo descuidados por los representantes del análisis estructural. La existencia de redes es en efecto la manifestación de relaciones históricamente consolidadas entre grupos u organizaciones. Por lo tanto, las redes constitutivas de un entorno partidista no son únicamente el resultado de la acción voluntarista de los actores políticos; su desarrollo y su activación aparecen coaccionados por una estructura históricamente objetivada en instituciones y reglas. Las relaciones familiares y el recuerdo de las luchas políticas pasadas y de los servicios brindados contribuyen a inscribir las redes en el tiempo (Abélès, 1989: 223). Pero si bien las organizaciones quedan marcadas por las condiciones originales que antecedieron su

25 Una buena presentación de esta corriente, a veces llamada "Escuela de Manchester", puede ser encontrada en Mitchell (1969) y Boissevain y Mitchell (1973). 
institucionalización, cambios de todo tipo afectan ininterrumpidamente la red de redes constitutiva del entorno partidista.

Estar atento a la evolución de las redes mediante las cuales un partido se arraiga en una sociedad determinada, es precisamente estar en condiciones de identificar cómo los cambios que intervienen desde fuera de la política (por ejemplo en el modo de reclutamiento de los docentes, en la organización del sindicalismo a raíz de los cambios económicos, en la Iglesia debido a la marginalización de las asociaciones de acción católica...) afectan a los partidos políticos, agotando sus redes tradicionales de influencia. A la inversa, el análisis del ingreso al partido de nuevos miembros que disponen de otras relaciones sociales (por ejemplo en el mundo empresarial o en la alta administración como sucedió en el PS francés a finales de los años setenta y sobre todo luego de su llegada al poder en 1981) puede ayudar a comprender los cambios en los equilibrios internos del partido y la descalificación de ciertos dirigentes que no cuentan con los mismos contactos.

Por supuesto, el enfoque de los partidos políticos mediante el análisis de redes no debe llevar a perder de vista el trabajo específico realizado a nivel de la organización partidaria stricto sensu para producir una unidad, una identidad común, por ejemplo por medio de la difusión de símbolos (himnos, emblemas, eslóganes...) o de la literatura partidaria, de las prácticas de formación, de los llamados al orden, del control de los recursos financieros. Un partido, salvo caso límite, no se resume entonces a una red de redes. Es también una institución con sus propias reglas, escritas y no escritas, que se imponen a los miembros más involucrados en ésta. Sus dirigentes deben también lidiar con las coacciones propias del régimen político y del sistema electoral en los cuales despliegan sus actividades. El modo de escrutinio, las reglas de financiamiento de los partidos políticos, el carácter parlamentario o presidencial del régimen, la facilidad más o menos grande para reformar la Constitución, todas estas "variables" afectan en sobre medida las estrategias pero también la organización de los partidos políticos. Muy a menudo los teóricos de los partidos quieren a toda costa imponer su definición como la única posible, olvidando que un partido es una realidad social compleja, caleidoscópica, cuya definición depende primero de la problemática planteada, es decir de las preguntas formuladas por el investigador. Definir el partido como un entorno partidista y una red de redes consiste ni más ni menos que en darse los medios para comprender mejor cómo un partido se ancla en la sociedad, cómo este anclaje evoluciona según los lugares y las épocas; permite también aclarar algunas de las opciones políticas tomadas por determinado partido, ceteris paribus.

\section{BIBLIOGRAFÍA}

Abélès, Marc (1986): “L'anthropologue et le politique", L'Homme, 26 (1-2), pp. 191-212.

(1989): Jours tranquilles en 89. Ethnologie politique d'un département français, Odile Jacob, París.

Barnes, John A. (1969): "Networks and Political Process", en J. C. Mitchell (ed.): Social Networks in Urban Situations, Manchester University Press, Manchester, pp. 51-76. 
Boltanski, Luc (1973): "L'espace positionnel. Multiplicité des positions institutionnelles et habitus de classe", Revue Française de Sociologie, 14 (1), pp. 3-26.

Bonnet, Serge (1972): Sociologie politique et religieuse de la Lorraine, Armand Colin, París.

Boissevain, Jeremy y James Clyde Mitchell (eds.) (1973): Networks Analysis, Mouton \& Co, La Haye.

Boissevain, Jeremy (1974): Friends of Friends. Networks, Manipulators and Coalitions, Basil Blackwell, Oxford.

Bourdieu, Pierre (1981): "La représentation politique. Éléments pour une théorie du champ politique", Actes de la Recherche en Sciences Sociales, 36/37, pp. 3-24.

(1984): "La délégation ou le fétichisme politique", Actes de la Recherche en Sciences Sociales, 52/53, pp. 49-55.

Crozier, Michel y Ehrard Friedberg (1977): L'acteur et le système, Seuil, París.

Dobry, Michel (1986): Sociologie des crises politiques, Presses de Sciences Po, París.

Duverger, Maurice (1951): Les partis politiques, Armand Colin, París.

Eldersveld, Samuel (1964): Political Parties: A Behavioral Analysis, Rand McNally, Chicago.

Elias, Norbert (1981 [1970]): Qu'est-ce que la sociologie?, Pandora, Aix-en-Provence.

Fourcaut, Annie (1986): Bobigny, banlieue rouge, Éditions Ouvrières/Presses de Sciences Po, París.

Gramsci, Antonio (1983 [1933]): "Note sul Machiavelli, sulla politica e sullo stato moderno", traducido en Textes (1917-1934), Éditions Sociales, París, pp. 176-180.

Hannerz, Ulf (1983 [1980]): Explorer la ville. Éléments d'anthropologie urbaine, Éditions de Minuit, París.

Hastings, Michel (1991): Halluin la rouge: 1919-1939. Aspects d'un communisme identitaire: singularités écologiques et stratégies d'implantation, Presses Universitaires de Lille, Villeneuve d'Ascq.

Katz, Richard S. y Peter Mair (1995): "Changing Models of Party Organization and Party Democracy: The Emergence of the Cartel Party", Party Politics, 1 (1), pp. 5-28.

Kirchheimer, Otto (1966): "The Transformation of the Western European Party Systems", en Joseph LaPalombara y Myron Weiner (eds.): Political Parties and Political Development, Princeton University Press, Princeton, pp. 177-200.

Knoke, David (1990): Political Networks. The Structural Perspective, Harvard University Press, Cambridge.

Koole, Ruud (1996): "Cadre, Catch-All or Cartel? A Comment on the Notion of the Cartel Party", Party Politics, 2 (4), pp. 507-523.

Lacroix, Bernard (1985): "Ordre politique et ordre social. Objectivisme, objectivation et analyse du politique", en M. Grawitz y J. Leca (dir.): Traité de science politique, vol. 1, Presses Universitaires de France, París, pp. 469-565.

Lagroye, Jacques (1989): “Change and Permanence in Political Parties", Political Studies, 37 (3), pp. 362-375.

LaPalombara, Joseph y Myron Weiner (eds.) (1966): Political Parties and Political Development, Princeton University Press, Princeton.

Latour, Bruno (2005): Re-assembling the Social: An Introduction to Actor-network Theory, Oxford University Press, Oxford.

Lavau, Georges (1953): Partis politiques et réalités sociales, Armand Colin, París. 
Lazar, Marc (1992): Maisons rouges. Les partis communistes français et italiens de la Libération à nos jours, Aubier, París.

Lazega, Emmanuel (2001): The Collegial Phenomenon. The Social Mechanisms of Cooperation among Peers in a Corporate Law Partnership, Oxford University Press, Oxford.

Lipset, Seymour y Stein Rokkan (eds.) (1967): Party Systems and Voter Alignment, The Free Press, New York.

Mattina, Cesare (2004): "Mutations des ressources clientélaires et construction des notabilités politiques à Marseille (1970-1990)", Politix, 67, pp. 129-155.

(2007): "Changes in Clientelism and Urban Government: A Comparative Case Study of Naples and Marseille", International Journal of Urban and Regional Research, 31 (1), pp. 73-90.

Michels, Robert (1971 [1911]): Les partis politiques. Essai sur les tendances oligarchiques dans les démocraties, Flammarion, París.

Mitchell, James Clyde (ed.) (1969): Social Networks in Urban Situations, Manchester University Press, Manchester.

Molinari, Jean-Paul (1991): Les ouvriers communistes, L'Albaron, Thonon-les-Bains.

Noiriel, Gérard (1984): Longwy, immigrés et prolétaires (1880-1980), Presses Universitaires de France, París.

(1986): Les ouvriers dans la société française. XIXe-XXe siècle, Seuil, París.

Offerlé, Michel (1987): Les partis politiques, Presses Universitaires de France, París.

Ostrogorski, Moisei (1993 [1903]): La démocratie et les partis politiques, Fayard, París.

Panebianco, Angelo (1988 [1982]): Political Parties. Organization and Power, Cambridge University Press, Cambridge.

Podolny, Joel M. y Karen L. Page (1998): “Network Forms of Organization”, Annual Review of Sociology, 24, pp. 57-76.

Pombeni, Paolo (1992 [1985]): Introduction à I'histoire des partis politiques, Presses Universitaires de France, París.

Pudal, Bernard (1988): Prendre parti. Pour une sociologie historique du PCF, Presses de Sciences Po, París.

Retière, Jean-Noël (1994): Identités ouvrières. Histoire sociale d'un fief ouvrier en Bretagne. 19091990, L'Harmattan, París.

Sartori, Giovanni (1990 [1968]): “The Sociology of Parties: A Critical Review”, en Peter Mair (ed.): The West European Party System, Oxford University Press, Oxford, pp. 150-182.

Sawicki, Frédéric (1997): Les réseaux du Parti socialiste. Sociologie d'un milieu partisan, Belin, París.

Sawicki, Frédéric y Philippe Vervaeke (eds.) (2008): Dossier: "La fabrique des partis en GrandeBretagne", Politix, 81 (21).

Schlesinger, Joseph A. (1965): "Political Party Organization", en J. G. March (ed.): Handbook of Organizations, Rand McNally, Chicago, pp. 764-801.

Schumpeter, Joseph (1990 [1942]): Capitalisme, socialisme et démocratie, Payot, París.

Schwartz Mildred A. (1990): The Party Network: The Robust Organization of Illinois Republicans, University of Wisconsin Press, Madison. 
Seiler, Daniel-Louis (1980): Partis et familles politiques, Presses Universitaires de France, París.

Weber, Max (1971 [1922]): Économie et société, Plon, París.

Wellmann, Barry y Steven D. Berkowitz (eds.) (1988): Social Structures. A Network Approach, Cambridge University Press, Cambridge. 
